\title{
Ideology in Critical Metonymy Analysis
}

\author{
Qiang Zhang ${ }^{1}$ \\ ${ }^{1}$ School of Foreign Languages, Shandong Jiaotong University, China \\ Correspondence: Qiang Zhang, School of Foreign Languages, Shandong Jiaotong University, Jinan 250357, \\ Shandong, China. E-mail: 170983040@qq.com
}

Received: March 3, 2014 Accepted: April 4, 2014 Online Published: May 27, 2014

doi:10.5539/ijel.v4n3p67

URL: http://dx.doi.org/10.5539/ijel.v4n3p67

\begin{abstract}
Ideology is an important concept in Critical Metonymy Analysis. In recent years, with the establishment of critical cognitive linguistics, the critical metonymy analysis has become a beneficial complement to this research paradigm. So, there is a unique connotation in ideology under the perspective of critical metonymy analysis. Critical metonymy analysis can be regarded as a weak version of ideology, which is different from the strong version of critical discourse analysis. In this paper, the author first makes a detailed introduction on the linguistic foundation and components of critical metonymy analysis. Then the author explores to analyze the mutual effects of ideology and the components in critical metonymy analysis. Finally the author concluded that this paper has provided a certain kind of orientation on ideology which is an important concept in critical metonymy analysis.
\end{abstract}

Keywords: critical discourse analysis, critical cognitive analysis, critical metonymy analysis, ideology

\section{Introduction}

With the development of metaphorical research, many linguists began to focus their attention on the research of metonymy in recent years. In the Chinese academics, many splendid academic papers and monographs have sprung up in recent years. The academic monograph Cognitive Metonymy written by Zhang Hui and Lu Weizhong, which was published in 2010, is regarded as the representative of the research of metonymy. As for academic papers, if we input "metonymy" as the key word into the search bar of CNKI, we would find up to 955 academic papers during the year of 2000 to 2010. As an essential part of cognitive linguistic theory, the research on metonymy also aroused the attention from other research fields of linguistics, such as critical discourse analysis. Stockwell (2007) proposed the theoretical method of critical cognitive linguistics by integrating cognitive linguistics and critical discourse analysis. In this paper, the critical metonymy analysis could be regarded as a complement for this theory. Ideology is one of the essential concepts in critical discourse analysis, so when analyzing the critical metonymy, we should clarify the ideology's theoretical connotation in the framework of critical metonymy.

\section{Methodology}

When writing this paper, the author used literature analysis method to collect pertinent literature and studied on the relevant theories about ideology and critical metonymy analysis. Then the author concluded and explained the relationship among ideology and other elements in critical metonymy analysis from the thesis and monographs by using the qualitative analysis methodology.

Another important methodology in this paper is inductive analysis. With the explanation of ideology and critical analysis as well as their mutual effects, the author finally reached an induction that through the combination of the analytical results of critical metonymy analysis and other methodologies (such as critical metaphor analysis), one can reproduce the comprehensive ideological meaning behind the discourse.

\section{Critical Metonymy Analysis}

\subsection{Critical Cognitive Linguistics}

The rapid development of cognitive linguistics has sparked the strong interest of the scholars. Thus many interdisciplinary theoretical systems has emerged, such as cognitive sociolinguistics ( $\mathrm{Su}, 2009$ ), critical cognitive linguistics (Zhang \& Jiang, 2008), etc. These new theoretical systems have paved the way for the further development of cognitive linguistics. 
Stockwell (2007) proposed an idea of establishing a new methodology of cognitive linguistics, namely critical cognitive linguistics. His original intention was to rouse the attention from the academic circles and a discussion on this theory. He pointed out that the references drawn from cognitive linguistics are as follows: cognitive linguistics provides more approaches for critical discourse analysis. And it also provides a method of theorizing metaphoric expression, foreground and background, social and customary category and attentiveness. So it is necessary and possible to establish the discipline of critical cognitive linguistics by combining cognitive linguistics and critical discourse analysis (Zhang \& Jiang, 2008, p. 18). Actually, before critical cognitive linguistics was proposed, Charteris-Black (2004) had already integrated critical discourse analysis and metaphor into a new theory called critical metaphor analysis. The critical metonymy analysis in this paper is also proposed based on this theory.

\subsection{Critical Metonymy Analysis}

In view of the introduction of cognitive linguistics and critical metaphor analysis, through analogy and introspection, we can integrate critical discourse analysis with metaphor and thus generate a new methodology on discourse analysis - critical metonymy analysis. This kind of paradigm could be regarded as a theoretical extension of critical discourse analysis. The so-called critical metonymy analysis utilizes some methods of critical discourse analysis to analyze and evaluate the metaphoric phenomenon in discourse systematically, hereby reveals the ideology reflected by the metonymic choice and the beliefs, minds and viewpoints of the discourse builders, and then provides a further interpretation of the discourses.

\subsubsection{Criticism}

The word criticism stems from the Greek word Krisis, meaning judgment or evaluation (Black, 2005, p. 29). Criticism includes at least two connotations: finding fault and making judgment, it is usually used for the comment on literature and arts. Criticism in critical metonymy analysis belongs to the latter connotation.

Researchers in different fields of study give different orientations concerning Criticism. There are various versions of concept about Criticism in literatures of critical discourse analysis. Wodak (1999) noted that criticism is the explanation of complicated phenomenon. Fairclough (2001) pointed out that critical discourse analysis includes not only analysis, but also criticism. Criticism plays a vital role in revealing the ideology in discourse, and it also undertakes the mission of triggering social innovation (Tia, 2009, p. 89). This proves the Criticism in critical discourse analysis is a concept related directly to social practice and innovation. The connotation of Criticism in critical metonymy analysis is different, and it is a matter of different degrees. Brockriede (1974) defined Criticism as "the behavior of evaluation or analysis". Andrews (1983) define Criticism as " $a$ systematical procedure of illustrating and evaluating the product of human activity". Based on the above research, Yuan (2008) proposed that criticism is a behavior of systematical analysis and evaluation. The connotation of this type of Criticism is consistent with the Criticism in critical metonymy analysis.

As for the inclination of Criticism, Maingueneau (2006, p. 230) made a detailed division on the critical inclination of discourse analysis, and divide the critical perspective into strong version and weak version: strong version refers to the activity of combining the textual structure and the system of social practice, while weak version refers only to the activity of depicting the textual structure. According to Maingueneau's research, we can conclude that the Criticism in critical metonymy belongs to the category of weak version.

\subsubsection{Metonymy}

In terms of traditional rhetoric, metonymy is regarded as a rhetorical device to substitute one thing for another, and it is a kind of decoration in people's communication (Li \& Fang, 2003, p. 53). In cognitive linguistics, metonymy is a kind of mechanism for people to cognize the objective world. The Metonymy in critical metonymy analysis mainly refers to the basic definition of metonymy made by restrictive cognitive linguistics (Note 1), that is, the relationship between ICM (Ideal Cognitive Mode) and the components of ICM as well as the relationship among the components of ICM (Note 2). For example:

(1) When Apple introduced the iPad six months ago, ushering in an era of tablet computing, experts predicted that tablets would transform the habits of groups of people like college students and doctors. (http://www.nytimes.comP2010P10P25PbusinessPmediaP25ipad. html?ref=technology)

In the example above, Apple refers to Apple Incorporated through metonymy device, because Apple and Apple Incorporated coexist in a same ICM. The application of metonymic relationship indicates the economic characteristics of a language.

In conclusion, the connotation of Metonymy in critical metonymy analysis is slightly different from its definition as Substitution in traditional rhetoric. From the perspective of discourse analysis, the Metonymy in critical 
metonymy analysis mainly refers to a kind of text corpus used for discourse analysis. Therefore, critical metonymy analysis is a kind of analytical methodology of analyzing and evaluating the metonymic phenomenon in discourse based the connotation of Criticism and Metonymy.

Modern linguists reckon that ideology could be transmitted by penetrating the conceptual metonymy mechanism. Goatly (2007, p. 249) claimed that ideology find its way into all kinds of discourses in a strict sense, the presentation of discourse must be presented from a particular angle. So we can conclude that the metonymic phenomenon in discourse could also contain a certain form of ideology. Moreover, ideology has its special meaning in the framework of critical metonymy analysis.

\section{Ideology in Critical Metonymy Analysis}

\subsection{Ideology}

It is generally believed that the word Ideology was first proposed by the French linguist Destutt de Tracy in the early $19^{\text {th }}$ century. The French word idéologie is composed of idéo and logie, the former means idea in Greek language, and the latter means doctrine in Greek language. Therefore, according to Tracy, ideology could be regarded as the Science of Ideas. Because ideology treated the fundamental issues in epistemology as its own object of study from the very beginning, therefore the concept of ideology was considered as a philosophical concept when it was generated.(Yu, 2009, p. 28) Every scholar has his unique understanding about this concept due to different perspectives. Althusser (1971) claimed that ideology is not the absolute notion; however, it is closely associated with the concrete practice of the social institution. Eagleton (1991) pointed out that ideology itself is a text constituted by a large number of concepts. Zizek $(2002$, p. 4) noted that ideology could refer to everything: from the attitude toward the mediation of dependency on social reality to a whole set of beliefs on behavioral orientation, from the indispensible media which can sustain the relationship between an individual and the social structure, to the misconception of dominating the legalization of political power, it is almost embracive. On the whole, ideology could be seen as a kind of viewpoint, principle, representation or proposition. The various concepts of ideology can be summarized as follows: a) ideology contains derogatory meanings; b) the concept of ideology includes emotion and attitude; c) ideology could serve as a kind of perspective of value; d) ideology conflicts with reality, it is a twist of reality; e) ideology could serve as a methodology of criticizing and judging incidents (Huaco, 1971, p. 246).

The concepts of ideology are so numerous that we should give them a certain classification. Geuss proposed three kinds of ideological concepts: the first concept is the ideology of a certain meaning, that is, to illustrate ideology in a neutral way when analyzing a certain social structure; the second concept is the ideology of affirmative meaning, which not only acknowledges the existence of ideology, but also hold an affirmative attitude toward its content and value; the third concept is the ideology of negative meaning, which acknowledges the existence of ideology, but considers that it can only cover the nature of social existence. Gramsci also classified the concept of Organic Ideology and Arbitrary Ideology. The former refers to the ideology of affirmative meaning, it is a reflective form of a certain social structure; the latter refers to the ideology of negative meaning, it is a personal speculation and a reflective form of misrepresented social history (Xin, 2005, p. 9).

Combining the research above, we intend to classify the ideology into strong version and weak version according to the relationship among ideology, social innovation and people's beliefs. The strong version refers to the close relationship between ideology and social form and system, in essence, ideology is the notion of ruling class. It is a set of notion proposed by the ruling class and a system of value imposed on the ruled class. The weak version refers to the methodology that people treat the objective world and the description of the world from a particular perspective. It could be regarded as a rhetorical motivation. Burke had proposed his viewpoint in his work $A$ Grammar of Motives that "Ideology should not be concluded only from the investigations of economy, but also from human's nature of utilizing the symbols." (1969, p. 146)

As an important concept in critical discourse analysis, ideology has its particular meaning in both critical discourse analysis and critical linguistics.

\subsection{Critical Discourse Analysis, Critical Linguistics and Ideology}

As a research paradigm, critical discourse analysis mainly focuses on the relationship among language, authority and ideology. Critical discourse analysis insists on the core of critical linguistics, meanwhile, it broadens the critical perspective of critical discourse analysis. The core content of critical discourse analysis is the study on the relationship between language structure and social structure, such as the exploration of power relationship and inequality in languages, or the revelation of ideology implied in discourse, or the exposal of inequality and 
injustice in discourse. (Van Dijk, 1993)

So we can draw the conclusion that the purpose of critical discourse analysis is to reveal the ideological meaning concealed in discourses, especially the prejudice, discrimination and distortion of facts which people are accustomed to. (Xin, 2002, p. 36) Through revealing the relationship between ideology and authority behind language, we can have a sober understanding of the discourse.

Because the ideology revealed by critical discourse analysis has a close relationship with the authority and the phenomenon of inequality reflected in discourse, and critical discourse analysis aims to explore how discourse reflect the social reality and participate the social innovation. So we can conclude that this kind of ideology belongs to strong version.

In critical linguistics, Fowler (1979, p. 190) proposed that ideology as a neutral concept. He pointed out that ideology could be regarded as beliefs, systems of value, viewpoints, perspectives or categories of understanding the world. He (1991, p. 92) went a step further to note that critical linguistics does not refer to some false ideas or twisted ideas. More properly, we can conclude that ideology is a neutral definition, which is closely associated with people's arrangement and demonstration of their life styles. Kress and Hodge (1979, p. 6) also regarded ideology as a descriptive concept. Ideology in critical linguistics actually belongs to the weak version category. It aims to reveal the viewpoints, beliefs and ideas of discourse builders.

In effect, the ideology in critical metonymy is in accordance with the ideology in critical linguistics which belongs to the weak version category. It aims to reveal the connotative beliefs, ideas and rhetorical motivation through the metonymic phenomenon in discourse.

\subsection{Metonymy and Ideology}

Ideology penetrates every corner of the language. A certain ideology always takes the language as a carrier. Metonymy also undertakes a certain kind of ideological meaning. Because ideology is a part of our cognition, that is, the social cognition, so the analysis of basic cognition features in cognitive linguistics could be regarded as a useful tool in analyzing different ideologies and provides the analytical basis on analyzing the performance of ideology in languages. (Hong \& Zhang, 2002, p. 6) As an important component in cognitive linguistics, metonymy could also become an essential way of analyzing the ideology in discourse.

As is mentioned above, the option of metonymy indicates the rhetorical motivation of discourse builders. This kind of rhetorical motivation reflects the methodology of viewing things from a particular angle, and it is the ideology of weak version. Therefore, as a particular figure of speech, there is an extraordinary intention in the option of metonymy. The existence of rhetorical devices is by no means the requirement of language forms or techniques but closely related to some kind of outlook on world and values. (Mao, 2008, p. 107) Metonymy could also reflect some kind of outlook on values. It can guide the readers to interpret the discourses from a particular ideological perspective and realize the purpose of influencing the readers. Metonymy could not only reflect our physical and spiritual experience, but also create the reality especially the social reality for us. In the process of creating the reality, metonymy could also construct the social relationship and identity, thereby reflecting the attitudes and outlooks of the discourse builders. For example:

\section{(2) Trawler captain heading home}

Zhan flying back to Fujian after being held for two weeks in Japan.

BEIJING-Japan said on Friday it was freeing the Chinese trawler captain it had held since collisions off the Diaoyu Islands two weeks ago. The detention of 41-year-old Zhan Qixiong sparked the most serious row between the Asian giants for many years. In announcing their decision to free Zhan, Japanese prosecutors said the deepening rift between Beijing and Tokyo played a role in their deliberations. (http://www.chinadaily.com.cn/china/2010-09/25/content-11341681. htm)

In the example above, the metonymic option of Beijing and Tokyo reflects a certain kind of ideological meaning. They refer to Chinese government and Japanese government respectively in a metonymic way. The Japanese prosecutors using such metonymic expression intended to conceal the political responsibility in order to avoid mentioning the Chinese and Japanese government, because the detention of Chinese captain has roused the divergence between the two countries. The use of this kind of metonymic expression stimulates certain feelings of the discourse interpreters and affects their way of thinking. It also reflects the neutral outlook on values of the discourse builders.

\subsection{Criticism, Ideology and Terministic Screen}

Bell (1960) put forward that ideology could mask the objective world. Removing the veil of ideology could 
reveal the objective viewpoints of language. Concealment is an important feature of ideology; therefore, we should remove the concealment of ideology by means of criticism and cognize the truth of the real world. The feature of ideology is similar with the concept of terministic screen proposed by rhetorician Burke. He was inspired by the camera lenses and color filter when taking photos, and called all the symbolic systems or collection of words as terministic screen. (Liu, 2008, p. 339) Different verbal signs constitute different terministic screens which make the realistic features more prominent and other features more desalinated. The words can classify the selective and prominent concepts in reality. We live in a world filled with words all the time; it could restrict our way of thinking, emotional world and social activities. Terministic screen indicates the motivation of the speakers, and different verbal signs constitute different terministic screens. They could steer the ideology of listeners and the motivation of the speakers is reflected in the construction of verbal signs. (Ju, 2010, p. 43)

The concept of terministic screen indicates that it constitutes a unique perspective of cognizing the world. In the process of cognizing the world, people always emphasize some features; in the meantime, the other features would be concealed. For instance, when discourse builders are choosing a certain metonymic expression, they are in fact emphasizing a certain part of ICM; accordingly, the other parts would be neglected. Therefore, metonymy is relevant to terministic screen in a certain sense. Metonymy cognizes and also reflects the entirety through prominent parts in cognition or the parts that could be understood more easily. Now that the discourse builders choose the prominent parts, the other parts are always neglected. So the option of prominent parts could reflect an ideological meaning.

As is mentioned above, the ideology in critical metonymy analysis can be regarded as an ideology of weak version. Studying metonymic phenomenon could penetrate the terministic screen established by metonymic expression and reveal the ideological meaning behind it.

\section{Conclusion}

Critical metonymy analysis is a kind of research paradigm which integrates critical discourse analysis and metonymy. This analytical methodology could be regarded as a theoretical complement to critical discourse analysis as well as a theoretical extension of critical cognitive linguistics. Critical metonymy analysis reveals the relationship among the human-being, languages, thoughts and realities. This paper provides a certain kind of orientation on ideology which is an important concept in critical metonymy analysis. Researches show that ideology belongs to weak version under the perspective of critical metonymy analysis; it is a rhetorical motivation of people's viewpoints, beliefs and attitudes in regarding the world.

The Criticism in critical metonymy analysis belongs to weak version and does not interrelated with social innovation, and it is just a discourse analytical methodology describing the texts; in addition, because the ideology in critical metonymy analysis is of weak version, so critical metonymy analysis is a more advanced research paradigm than the traditional discourse analysis. It not only describes the language, but also reveals some additional information implied in the language - the ideological meaning and rhetorical motivation. The metonymy in discourse reflects people's attitude toward the world, the different options of metonymy are bound to draw our attention to the totally different features in a same object. Therefore, the aim of criticism is to recognize the concealed function of terministic screen and reproduce the ideology and linguistic reality in discourse.

Admittedly, the ideological meaning in discourse could not only be reflected through the metonymic phenomenon, and it could also be represented through other linguistic means (such as metaphor, theme and rheme in sentences). Therefore, the ideology reflected in metonymy is only a part of the whole ideological meaning in discourse and it cannot reflect the real features of the whole discourse. Only through the combination of the analytical results of critical metonymy analysis and other methodologies (such as critical metaphor analysis) can we reproduce the comprehensive ideological meaning behind the discourse.

\section{References}

Althusser, L. (1971). Lenin and Philosophy and Other Essays. New York: Monthly Review Press.

Andrews, J. R. (1983). The Practice of Rhetorical Criticism. New York: Macmillan Publishing.

Bell, D. (1960). The End of Ideology (revised edition). New York: The Free Press.

Black, E. (2005). On objectivity and politics in criticism. In J. A. Kuypers (Ed.), The Art of Rhetorical Criticism (pp. 28-32). Boston: Pearson Education.

Brockriede, W. (1974). Rhetorical criticism as argument. Quarterly Journal of Speech, 60(2), 165-174. 
http://dx.doi.org/10.1080/00335637409383222

Burke, K. A. (1969). A Grammar of Motives. California: University of California Press.

Charteris-Black, J. C. (2004). Approaches to Critical Metaphor Analysis. Basingstoke \& New York: Palgrave-Macmillan. http://dx.doi.org/10.1057/9780230000612

Eagleton, W. (1991). Ideology: An Introduction. London: Verso.

Fairclough, N. (2001). Language and Power (2nd ed.). London: Longman.

Fowler, R. (1991). Language in the News: Discourse and Ideology in the Press. London: Routledge. http://dx.doi.org/10.2307/415093

Fowler, R., Hodge, G., \& Trew, T. (1979). Language and Control. London: Routledge and Kegan Paul. http://dx.doi.org/10.1080/00207177908922810

Goatly, A. (2007). Washing the Brain-Metaphor and Hidden Ideology. Amsterdam: John Benjamins. http://dx.doi.org/10.1075/dapsac.23

Hong, Y.-Q., \& Zhang, H. (2002, February). Cognitive Linguistics and Ideology Research. Foreign Languages and Their Teaching, 2002(2), 5-9. http://dx.doi.org/10.3969/j.issn.1004-6038.2002.02.002

Huaco, G. A. (1971). On Ideology. Acta Sociologica, 14(4), 245-255. http://dx.doi.org/10.1177/000169937101400404

Ju, Y.-M. (2010). A study of Kenneth Burke's philosophy of language from his concept of "terministic screen". Modern Foreign Languages, 39-47.

Kress, G., \& Hodge, R. (1979). Language as Ideology. London: Routledge and Kegan Paul.

Li, Z.-Y., \& Fang, X.-Z. (2003). Ideal cognitive model and pragmatic function of metonymy. Shandong Foreign Language Teaching, 3, 53-57. http://dx.doi.org/10.3969/j.issn.1002-2643.2003.03.012

Liu, Y.-M. (2008). History of Western Rhetoric. Beijing: Foreign Language Teaching and Research Press.

Maingueneau, D. (2006). Is discourse analysis critical? Critical Discourse Studies, 2, 229-235. http://dx.doi.org/10.1080/17405900600908145

Mao, X.-G. (2008). The value and significance of rhetorical criticism. Journal of Social Science of Hunan Normal University, 4, 103-108. http://dx.doi.org/10.3969/j.issn.1000-2529.2008.04.023

Radden, G., \& KÊvecses, Z. (1999). Towards a theory of metonymy. In K. Panther, \& G. Radden (Eds.), Metonymy in Language and Thought (pp. 17-59). Amsterdam: John Benjamins.

Stockwell, P. (2007). Toward a critical cognitive linguistics. In A. Combrink, \& I. Biermann (Eds.), Poetics, Linguistics and History. London: Nottingham University Press.

$\mathrm{Su}$, X.-J. (2009). The social turn in cognitive linguistics. Journal of Foreign Languages, 5, 47-51.

Tian, H.-L. (2009). Discourse Studies: Categories, Perspectives and Methodologies. Shanghai: Shanghai Foreign Language Education Press.

Van Dijk, T. A. (1993). Principles of critical discourse analysis. Discourse \& Society, 2, 249-283. http://dx.doi.org/10.1177/0957926593004002006

Wodak, R. (1999). Critical discourse analysis at the end of the 20th century. Research on Language and Social Interaction, 32(1-2), 185-193. http://dx.doi.org/10.1080/08351813.1999.9683622

Xin, B. (2002).Critical Linguistics: Theory and Application. Journal of Foreign Languages, 6, 34-41. http://dx.doi.org/10.3969/j.issn.1004-5139.2002.06.005

Yu, W.-J. (2009). A Study on Ideology (revised edition). Beijing: People's Press.

Yuan, Y. (2008). Towards A New Model of Rhetorical Criticism. Shanghai International Studies University.

Zhang, H., \& Jiang, L. (2008). Integration of cognitive linguistics and critical discourse analysis. Foreign Language Research, 5, 12-19.

Zhang, H., \& Lu, W.-Z. (2010). Cognitive Metonymy. Shanghai: Shanghai Foreign Language Education Press. http://dx.doi.org/10.1016/j.cogdev.2009.12.001

Zizek. (2002). Drafted Ideology (Translated by Fang Jie). Nanjing: Nanjing Normal University Press. 


\section{Notes}

Note 1. Shen Jiaxuan proposed that in restrictive cognitive linguistics, the language competence has no essential difference with the general cognitive ability. Restrictive cognitive linguistics is not a branch of linguistics, but a new ideological trend in the linguistic field. It is not a unitary theory which represents a new research paradigm. It emphasizes on interpreting the close relationship between language and general cognitive ability. (Quoted from Zhang \& Lu, 2010, p. i)

Note 2. We adopt the definition of metonymy made by Radden and KÊvecses (1999). Because this concept is more fundamental and understandable, moreover, it includes more concrete and comprehensive metonymic relationships.

\section{Copyrights}

Copyright for this article is retained by the author(s), with first publication rights granted to the journal.

This is an open-access article distributed under the terms and conditions of the Creative Commons Attribution license (http://creativecommons.org/licenses/by/3.0/). 